\title{
The Interaction of Value and Momentum Strategies
}

\author{
Clifford S. Asness
}

Value and momentum strategies both have demonstrated power to predict the crosssection of stock returns, but are these strategies related? Measures of momentum and value are negatively correlated across stocks, yet each is positively related to the cross-section of average stock returns. We examine whether the marginal power of value or momentum differs depending upon the level of the other variable. Value strategies work, in general, but are strongest among low-momentum (loser) stocks and weakest among high-momentum (winner) stocks. The momentum strategy works, in general, but is particularly strong among low-value (expensive) stocks. These results hold despite finding comparable spreads in value measures among stocks with different levels of momentum and comparable spreads in the momentum measure among stocks with different levels of value. Any explanation for why value and momentum work must explain this interaction.

$\mathbf{R}$ esearchers have convincingly demonstrated that value strategies can be used to predict stock returns. For instance, Fama and French (1992) showed that value strategies based on a firm's ratio of book-to-market value of equity (BV/MV) have power to forecast stock returns. Similarly, Lakonishok, Shleifer, and Vishny (1994) showed that value strategies based on a firm's cash-flow-toprice ratio $(C / P)$ have power to forecast stock returns. Although conflicting explanations have been offered for the success of these strategies, the empirical evidence that they have worked is quite strong. ${ }^{1}$

Researchers have also convincingly demonstrated that momentum strategies have power to predict stock returns. For instance, Jegadeesh and Titman (1993) showed that strategies that buy winners and sell losers based on returns over the previous 6-12 months generate excess returns. Asness (1995) showed that these strategies are effective even after accounting for common value measures. In particular, they are most effective when the definition of momentum excludes returns over the most recent month. ${ }^{2}$ The evidence that momentum strategies work is convincing. As with the value strategies, however, the explanation of why they work is largely incomplete.

For this study, we examined whether value and momentum strategies are independent or related, asking how well value strategies work

Clifford S. Asness is a managing director at Goldman, Sachs $\mathcal{E}$ Company. among stocks that have exhibited both strong momentum (winners) and weak momentum (losers). Similarly, we looked at momentum strategies among only high-value (cheap) or only low-value (expensive) stocks. We found that value works, in general, but that it is particularly strong among loser stocks and quite weak among winner stocks. Momentum also works, in general, but is particularly strong among expensive stocks.

Our findings do not help distinguish between rational and irrational asset pricing. Consider our observation that value does not work for winner stocks. Assume first that value strategies work because variables such as book-to-market ratio are related to an underlying priced distress factor (the rational pricing case). In this case, $\mathrm{BV} / \mathrm{MV}$ is certainly not a true risk-factor loading but simply a noisy proxy for such a loading. Conditional on a firm having a high $\mathrm{BV} / \mathrm{MV}$, it is likely to be distressed and thus load strongly on the risk factor related to distress. Also possible, however, is that conditional on a firm jointly having a high $\mathrm{BV} / \mathrm{MV}$ and high recent return, it is unlikely to be distressed. In other words, strong recent returns indicate that distress is unlikely no matter what the BV/ $\mathrm{MV}$. Because this firm is not distressed, it does not load strongly on the distress factor and has no corresponding expected return premium over winners with lower BV / MVs. Put differently, winners, no matter what their BV/MVs, are not generally distressed. Thus, our results can be consistent with $\mathrm{BV} / \mathrm{MV}$ being a noisy proxy for a distress factor in a rational asset-pricing model.

Next, assume that value strategies work not 
because of rational pricing of risk but because investors are "uncomfortable" with holding the assets found cheap by value measures (one version of the irrational case). Investors willing to hold these uncomfortable assets receive an expected return premium. Also possible is that no matter what an asset's $\mathrm{BV} / \mathrm{MV}$, investors are never uncomfortable with recent winners, and hence, owning these stocks does not earn a return premium. Because our results can fit both explanations, they do not distinguish between the rational and irrational stories for the success of value and momentum strategies. Our results, however, do add to the set of stylized facts that the ultimate explanation must cover.

In general, value and momentum are related, and the cross-section of expected stock returns is more complicated than previously thought.

\section{DATA AND METHODOLOGY}

We ran tests on monthly data from July 1963 through December 1994 on all NYSE, Amex, and Nasdaq firms with the necessary CRSP and Compustat data.

A stock's PAST $(2,12)$ is its average monthly return during the past 12 months, excluding the most recent one. A stock's MV is the CRSPcalculated number of shares outstanding times price per share, both measured at the end of the prior month. A stock's BV is the firm's book value of common equity for the prior year. BV is updated in July to include data only up through the prior December. Thus, the lag between its measurement and our tests is sufficient to ensure that our trading strategies contain little, if any, "look-ahead bias." A stock's $\log (\mathrm{BV} / \mathrm{MV})$ is the logged ratio of these quantities. A stock's D/P is the total value of its common dividends last year divided by MV. Like $\mathrm{BV}, \mathrm{D}$ is measured with a December-to-July lag. ${ }^{3}$

Both $\log (\mathrm{BV} / \mathrm{MV})$ and $\mathrm{D} / \mathrm{P}$ are variables commonly used in value strategies. Asness and Stevens (1995) showed that value strategies are generally more effective when variables are measured within industries. Intraindustry measurement means that when measuring a firm's $\log (\mathrm{BV} / \mathrm{MV})$ or $\mathrm{D} / \mathrm{P}$, we subtracted the value-weighted average of the $\log (\mathrm{BV} / \mathrm{MV}) \mathrm{s}$ or D/Ps for that firm's industry. We defined 49 industries as in Fama and French (1994a) and Asness and Stevens and constructed intraindustry measures of $\log (\mathrm{BV} / \mathrm{MV})$ and $\mathrm{D} / \mathrm{P}$. Thus, on our scale, a value stock is one with high $\log (\mathrm{BV} /$ $\mathrm{MV}$ ) or D/P relative to its industry.

We constructed value-weighted portfolios based on three variables: PAST $(2,12)$, industryrelative $\log (\mathrm{BV} / \mathrm{MV})$, and industry-relative $\mathrm{D} / \mathrm{P}$. For each month, we sorted all NYSE firms independently on each of the variables into five portfolios. We then placed each NYSE, Amex, or Nasdaq firm into one of the quintiles based on the NYSE breakpoints. Tables 1 through 3 report the average monthly return on each value-weighted portfolio, the summed full-period beta from regressing each quintile's return on the value-weighted NYSE/ Amex/Nasdaq portfolio (contemporaneous and lagged one month), the average value-weighted size firm in each quintile (averages are over each month and each firm), the average value-weighted $\log (\mathrm{BV} / \mathrm{MV})$ for each quintile, the average valueweighted $\mathrm{D} / \mathrm{P}$ for each quintile, and the average value-weighted $\operatorname{PAST}(2,12)$ for each quintile.

We also formed intersections of the above quintile portfolios. For example, 25 portfolios were based on the intersection of PAST $(2,12)$ and intraindustry $\log (\mathrm{BV} / \mathrm{MV})$ breakpoints. These results are reported in Tables 4 and 5.

\section{UNIVARIATE TESTS}

We first examined the properties of value-weighted quintile portfolios formed by sorting on each variable individually. Table 1 reports results for the $\operatorname{PAST}(2,12)$ variable. The last column contains the difference in average return between $Q 5$ (highest PAST[2,12] firms) and Q1 (lowest PAST[2,12] firms) and a $t$-statistic testing if the mean return is zero.

This table reconfirms the results of Jegadeesh and Titman (1993) and Asness (1995). Returns are increasing in past recent returns ( $Q 5$ has 0.87 percent higher average monthly return than $Q 1$ ), and this

Table 1. Sorting on PAST(2,12)

\begin{tabular}{lcccccc}
\hline Statistic & $Q 1$ & $Q 2$ & $Q 3$ & $Q 4$ & $Q 5$ & $\begin{array}{c}Q 5-Q 1 \\
(t \text {-Statistic) }\end{array}$ \\
\hline Monthly return & $0.61 \%$ & $0.80 \%$ & $0.81 \%$ & $1.09 \%$ & $1.48 \%$ & $0.87 \%$ \\
Beta & 1.14 & 0.92 & 0.96 & 0.93 & 1.17 & $(3.73)$ \\
Size (millions) & $\$ 5,879$ & $\$ 9,207$ & $\$ 9,418$ & $\$ 9,323$ & $\$ 7,963$ & \\
Log(BV/MV) & -0.51 & -0.62 & -0.73 & -0.86 & -1.12 & \\
D/P & $3.90 \%$ & $3.99 \%$ & $3.68 \%$ & $3.19 \%$ & $2.15 \%$ & \\
PAST(2,12) & $-1.52 \%$ & $0.01 \%$ & $1.12 \%$ & $2.29 \%$ & $4.64 \%$ & \\
\hline
\end{tabular}


relationship is statistically significant. Beta shows a small U-shaped relation to PAST $(2,12)$, and size has a corresponding inverted U-shape. $\log (\mathrm{BV} / \mathrm{MV})$, and to a lesser extent $\mathrm{D} / \mathrm{P}$, is falling in $\operatorname{PAST}(2,12)$. Part of this decline is by construction. Dividends and book value were measured over the prior fiscal year with a measurement lag from December until July. If true current $\mathrm{D} / \mathrm{P}$ and $\mathrm{BV} / \mathrm{MV}$ were unrelated to PAST $(2,12)$, our reported $\mathrm{D} / \mathrm{P}$ and $\mathrm{BV} / \mathrm{MV}$ might still be related to PAST $(2,12)$ because of PAST $(2,12)$ 's connection with $\mathrm{D} / \mathrm{P}$ and $\mathrm{BV} / \mathrm{MV}^{\prime}$ 's denominator (i.e., MV is positively related to recent return). Finally, by construction, $Q 1$ through $Q 5$ show monotonically increasing PAST $(2,12)$.

In Table 2, returns are increasing in $\log (\mathrm{BV} /$ $\mathrm{MV})$, and this increase is statistically significant. Betas are somewhat U-shaped. After Q1, average firm size is falling in $\log (\mathrm{BV} / \mathrm{MV})$. By construction, $\log (\mathrm{BV} / \mathrm{MV})$ is increasing across the quintiles. Similarly, $\mathrm{D} / \mathrm{P}$ is also increasing in $\log (\mathrm{BV} / \mathrm{MV})$, but PAST $(2,12)$ is falling. $\log (\mathrm{BV} / \mathrm{MV})$ and $\operatorname{PAST}(2,12)$ are both positively and significantly associated with future returns, yet they are negatively associated with each other.

For the univariate sorts on $\mathrm{D} / \mathrm{P}$ (Table 3), returns are increasing in $\mathrm{D} / \mathrm{P}$, but this increase is weak relative to that of the other variables. $Q 1$ to Q4 exhibit flat average returns, with returns finally increasing at $Q 5$. The $Q 5-Q 1$ spread is 31 basis points a month, which is marginally significant. Thus, univariately, industry-relative dividend yield is a weaker predictive variable than is BV/ MV. Beta is generally falling in D/P. Firm size is shaped like an inverted U-both the highest and lowest $\mathrm{D} / \mathrm{P}$ firms are generally smaller than the others. Sorting on industry-relative $\mathrm{D} / \mathrm{P}$ induces no relation in $\log (\mathrm{BV} / \mathrm{MV})$ for $Q 1$ to $Q 3$ but has an increasing relation for $Q 4$ and $Q 5$. Industry-relative $\mathrm{D} / \mathrm{P}$ is negatively related to $\operatorname{PAST}(2,12)$.

We drew two conclusions from the univariate tests. First, each variable is univariately positively associated with future expected returns (the relation is marginal for $\mathrm{D} / \mathrm{P}$ ). Second, the value variables $(\log [\mathrm{BV} / \mathrm{MV}], \mathrm{D} / \mathrm{P})$ and momentum (PAST 2,12$])$, are positively associated with future expected returns but negatively associated with each other.

\section{SORTING ON BOTH VARIABLES}

The empirical evidence that value strategies work is convincing. Value measures are negatively associated with momentum, however, which is itself positively associated with returns. In such a case, we would expect value to work better as a predictor of returns holding momentum constant and momentum to work better holding value constant. We do not, however, necessarily expect these marginal relations to differ across varying momentum or value quintiles. Sorting on two variables at once, we tested whether the two strategies are each stronger holding the other constant and whether the marginal relations do in fact vary.

Table 4 reports results of sorting firms on both $\operatorname{PAST}(2,12)$ and intraindustry $\log (\mathrm{BV} / \mathrm{MV})$. That is, we took the intersection of the $\operatorname{PAST}(2,12)$ and $\log (\mathrm{BV} / \mathrm{MV})$ quintiles to form 25 value-weighted portfolios with monthly returns from July 1963 to December 1994. For instance, the upper left entry in Table 4 represents the portfolio of firms that fall into the lowest value quintile and the lowest momentum quintile each month.

Table 2. Sorting on Industry-Relative Log(BV/MV)

\begin{tabular}{lcccccc}
\hline Statistic & $Q 1$ & $Q 2$ & $Q 3$ & $Q 4$ & $Q 5$ & $\begin{array}{c}Q 5-Q 1 \\
(t \text {-Statistic) }\end{array}$ \\
\hline Monthly return & $0.85 \%$ & $0.89 \%$ & $0.98 \%$ & $1.24 \%$ & $1.36 \%$ & $0.51 \%$ \\
Beta & 1.09 & 0.88 & 0.86 & 1.09 & 1.22 & $(3.18)$ \\
Size (millions) & $\$ 9,811$ & $\$ 13,618$ & $\$ 7,254$ & $\$ 3,386$ & $\$ 3,325$ & \\
$\log (\mathrm{BV} / \mathrm{MV})$ & -1.47 & -0.85 & -0.43 & -0.19 & 0.17 & \\
D/P & $2.04 \%$ & $3.29 \%$ & $4.13 \%$ & $4.14 \%$ & $6.54 \%$ & \\
PAST(2,12) & $2.13 \%$ & $1.41 \%$ & $1.10 \%$ & $0.89 \%$ & $0.66 \%$ & \\
\hline
\end{tabular}

Table 3. Sorting on Industry-Relative D/P

\begin{tabular}{lcccccc}
\hline Statistic & $Q 1$ & $Q 2$ & $Q 3$ & $Q 4$ & $Q 5$ & $\begin{array}{c}Q 5-Q 1 \\
(t-S t a t i s t i c)\end{array}$ \\
\hline Monthly return & $0.92 \%$ & $0.91 \%$ & $0.87 \%$ & $0.97 \%$ & $1.23 \%$ & $0.31 \%$ \\
Beta & 1.22 & 1.05 & 0.96 & 0.84 & 0.93 & $(2.10)$ \\
Size (millions) & $\$ 2,697$ & $\$ 8,303$ & $\$ 12,564$ & $\$ 9,522$ & $\$ 6,658$ & \\
Log(BV/MV) & -1.01 & -1.08 & -0.96 & -0.52 & -0.09 & \\
D/P & $1.16 \%$ & $1.94 \%$ & $2.93 \%$ & $4.53 \%$ & $7.62 \%$ & \\
PAST(2,12) & $2.17 \%$ & $1.85 \%$ & $1.52 \%$ & $0.98 \%$ & $0.53 \%$ & \\
\hline
\end{tabular}


Table 4. Sorting on PAST(2,12) and Log(BV/MV) within Industry

\begin{tabular}{|c|c|c|c|c|c|c|}
\hline $\begin{array}{l}\text { Average Value-Weighted } \\
\text { Statistic }\end{array}$ & $\begin{array}{c}Q 1 \\
\text { (Expensive } \\
\log [\mathrm{BV} / \mathrm{MV}])\end{array}$ & $Q 2$ & $Q 3$ & $Q 4$ & $\begin{array}{c}\text { Q5 } \\
\text { (Cheap Log } \\
\text { [BV/MV]) }\end{array}$ & $\begin{array}{c}Q 5-Q 1 \\
(t-\text { Statistic })^{\mathrm{a}}\end{array}$ \\
\hline \multicolumn{7}{|l|}{ Loser PAST $(2,12)$} \\
\hline Monthly return & $0.03 \%$ & $0.49 \%$ & $0.80 \%$ & $0.83 \%$ & $1.00 \%$ & $0.97 \%$ \\
\hline $\log (\mathrm{BV} / \mathrm{MV})$ & -1.24 & -0.72 & -0.36 & -0.12 & 0.29 & $(4.38)$ \\
\hline $\mathrm{D} / \mathrm{P}$ & $2.31 \%$ & $3.28 \%$ & $4.07 \%$ & $4.34 \%$ & $6.04 \%$ & \\
\hline $\operatorname{PAST}(2,12)$ & -0.92 & -1.63 & -1.72 & -1.90 & -2.27 & \\
\hline \multicolumn{7}{|l|}{$Q 2$} \\
\hline Monthly return & $0.61 \%$ & $0.59 \%$ & $0.90 \%$ & $1.25 \%$ & $1.35 \%$ & $0.74 \%$ \\
\hline Log(BV/MV) & -1.23 & -0.72 & -0.37 & -0.13 & 0.20 & $(3.57)$ \\
\hline $\mathrm{D} / \mathrm{P}$ & $2.62 \%$ & $3.66 \%$ & $4.45 \%$ & $4.55 \%$ & $6.70 \%$ & \\
\hline $\operatorname{PAST}(2 / 12)$ & 0.03 & 0.03 & -0.01 & -0.02 & -0.04 & \\
\hline \multicolumn{7}{|l|}{ Q3 } \\
\hline Monthly return & $0.52 \%$ & $0.93 \%$ & $0.80 \%$ & $1.19 \%$ & $1.44 \%$ & $0.92 \%$ \\
\hline Log(BV/MV) & -1.31 & -0.78 & -0.41 & -0.18 & 0.19 & $(4.94)$ \\
\hline $\mathrm{D} / \mathrm{P}$ & $2.40 \%$ & $3.55 \%$ & $4.29 \%$ & $4.24 \%$ & $6.98 \%$ & \\
\hline $\operatorname{PAST}(2 / 12)$ & 1.12 & 1.13 & 1.11 & 1.10 & 1.10 & \\
\hline \multicolumn{7}{|l|}{$Q 4$} \\
\hline Monthly return & $0.99 \%$ & $0.97 \%$ & $1.17 \%$ & $1.45 \%$ & $1.68 \%$ & $0.69 \%$ \\
\hline $\log (\mathrm{BV} / \mathrm{MV})$ & -1.42 & -0.85 & -0.49 & -0.24 & 0.10 & (3.39) \\
\hline $\mathrm{D} / \mathrm{P}$ & $2.02 \%$ & $3.13 \%$ & $3.80 \%$ & $3.80 \%$ & $6.35 \%$ & \\
\hline $\operatorname{PAST}(2 / 12)$ & 2.32 & 2.28 & 2.26 & 2.27 & 2.28 & \\
\hline \multicolumn{7}{|l|}{ Winner PAST $(2,12)$} \\
\hline Monthly return & $1.50 \%$ & $1.44 \%$ & $1.49 \%$ & $1.60 \%$ & $1.62 \%$ & $0.13 \%$ \\
\hline $\log (\mathrm{BV} / \mathrm{MV})$ & -1.64 & -0.88 & -0.60 & -0.35 & 0.13 & $(0.65)$ \\
\hline $\mathrm{D} / \mathrm{P}$ & $1.32 \%$ & $2.32 \%$ & $2.69 \%$ & $2.80 \%$ & $6.34 \%$ & \\
\hline PAST(2/12) & 5.01 & 4.34 & 4.31 & 4.35 & 4.47 & \\
\hline $\begin{array}{l}\text { Return difference } \\
(t \text {-Statistic })^{\mathrm{b}}\end{array}$ & $\begin{array}{c}1.47 \\
(5.71)\end{array}$ & $\begin{array}{c}0.95 \\
(3.47)\end{array}$ & $\begin{array}{l}0.69 \\
(2.66)\end{array}$ & $\begin{array}{c}0.76 \\
(3.10)\end{array}$ & $\begin{array}{c}0.62 \\
(2.57)\end{array}$ & \\
\hline
\end{tabular}

a Zero-investment portfolio that is long the $Q 5$ column entry for each row and short the $Q 1$ column entry for that row; that is, it tests a long/short portfolio strategy based on the column variable that attempts to hold the row variable constant. We report the average return on this long/short portfolio strategy and the $t$-statistic for the test of whether this average return is zero.

${ }^{b}$ Test similar to that described in Footnote a but for long/short portfolios formed on the row variable that attempt to hold the column variable constant.

For each of these 25 portfolios, we report four measures: the average monthly return, the average value-weighted $\log (\mathrm{BV} / \mathrm{MV})$, the average valueweighted $\mathrm{D} / \mathrm{P}$, and the average value-weighted PAST $(2,12)$. The last column and the last row report the results of $t$-tests of specific long/short portfolios. These correspond to the long/short portfolio tests reported in Tables 1 through 3, but in Table 4, the long and short portfolios are formed only over single quintiles of the other variable. For instance, the top right entry in Table 4 is 0.97 percent, which means that a long/short portfolio that is long the highest quintile of $\log (\mathrm{BV} / \mathrm{MV})$ and short the lowest quintile of $\log (\mathrm{BV} / \mathrm{MV})$, building this long/ short portfolio using only firms in the lowest quintile of PAST $(2,12)$, returned an average of 97 basis points a month. In other words, this entry reports tests of a value strategy across only the past year's loser firms, whereas Table 2 tested a value strategy across all firms. Similarly, the bottom left entry, containing 1.47 percent, reflects tests of a momen- tum strategy across only the most expensive firms. The other entries are defined accordingly.

The spread in average return between $\log (\mathrm{BV} /$ MV) and any of the bottom four PAST $(2,12)$ quintiles is larger and statistically more significant than the spread for all firms (Table 2). In contrast, the return spread induced by $\log (\mathrm{BV} / \mathrm{MV})$ is almost nonexistent for the highest quintile of $\operatorname{PAST}(2,12)$ firms (winners).

If value and momentum are negatively related, and each is univariately positively related to stock returns, then value should work better if momentum is held relatively constant. Thus, the results for the winner quintile are surprising. Looking across the highest $\operatorname{PAST}(2,12)$ quintile (the winner row in Table 4$)$, sorting on $\log (\mathrm{BV} / \mathrm{MV})$ produces a spread in actual $\log (\mathrm{BV} / \mathrm{MV})$ (the second entry under the winner category) comparable to, if not larger than, the spread across other rows. In the case of these highest PAST $(2,12)$ firms, however, a comparable spread in average return is missing (it is only 0.13 percent and statistically insignificant). Essentially, 
value does not seem to work well for winner firms, despite the fact that our value measure differs substantially among these firms. ${ }^{5}$

The result is similar for momentum strategies across different value quintiles. Although momentum works within all value quintiles, it is much stronger for the most expensive firms (the second column of Table 4). Furthermore, these stronger momentum results are present even though the spread in actual momentum (the fourth row within each cell) among low-value firms is, if anything, smaller than the momentum spread among highvalue firms.

Figures 1 through 3 present these results graphically. Figure 1 plots the average return to each of the 25 portfolios. Clearly, returns are strongly increasing with value for loser firms. Sorting on value, however, produces very little spread in average return for winner firms. Sorting on momentum produces a very steep ascent in average return among expensive stocks. This ascent, however, is considerably slower among stocks that are cheap on the $\log (\mathrm{BV} / \mathrm{MV})$ scale.

\section{Figure 1. Return Surface for PAST $(2,12)$ and Log(BV/MV) Portfolios}

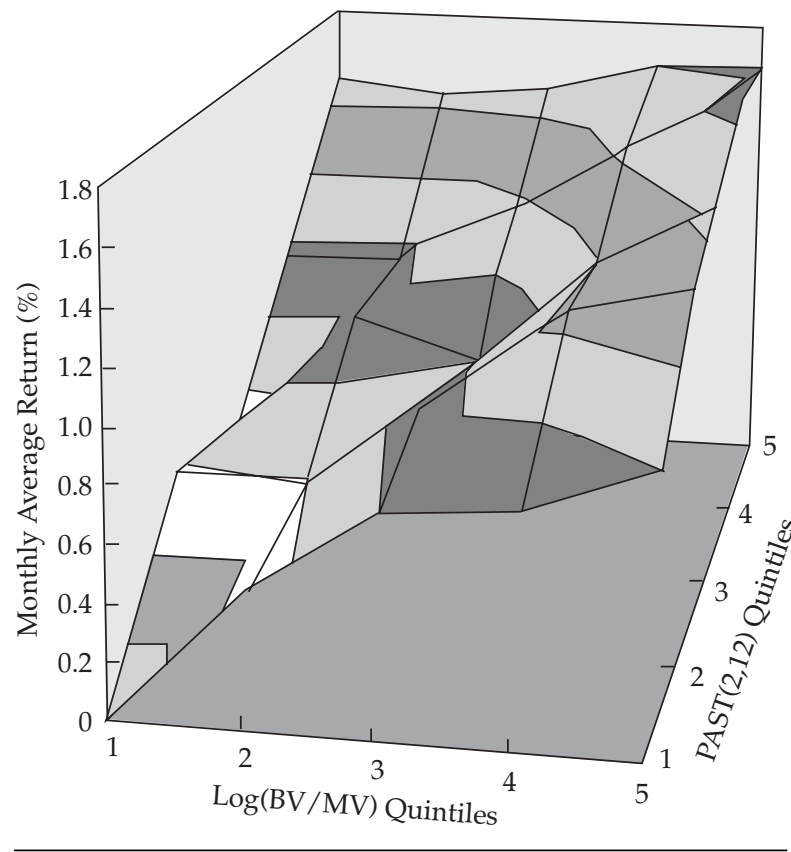

Figure 2 and Figure 3 plot the $\log (\mathrm{BV} / \mathrm{MV})$ and PAST $(2,12)$, respectively, on each portfolio. The sorting technique appears to be generally effective. Within $\log (\mathrm{BV} / \mathrm{MV})$ quintiles, sorting on PAST $(2,12)$ produces very little spread in $\log (\mathrm{BV} / \mathrm{MV})$. Similarly, within PAST $(2,12)$ quintiles, sorting on $\log (\mathrm{BV} / \mathrm{MV})$ produces very little
Figure 2. $\log (B V / M V)$ Surface for PAST $(2,12)$ and Log(BV/MV) Portfolios

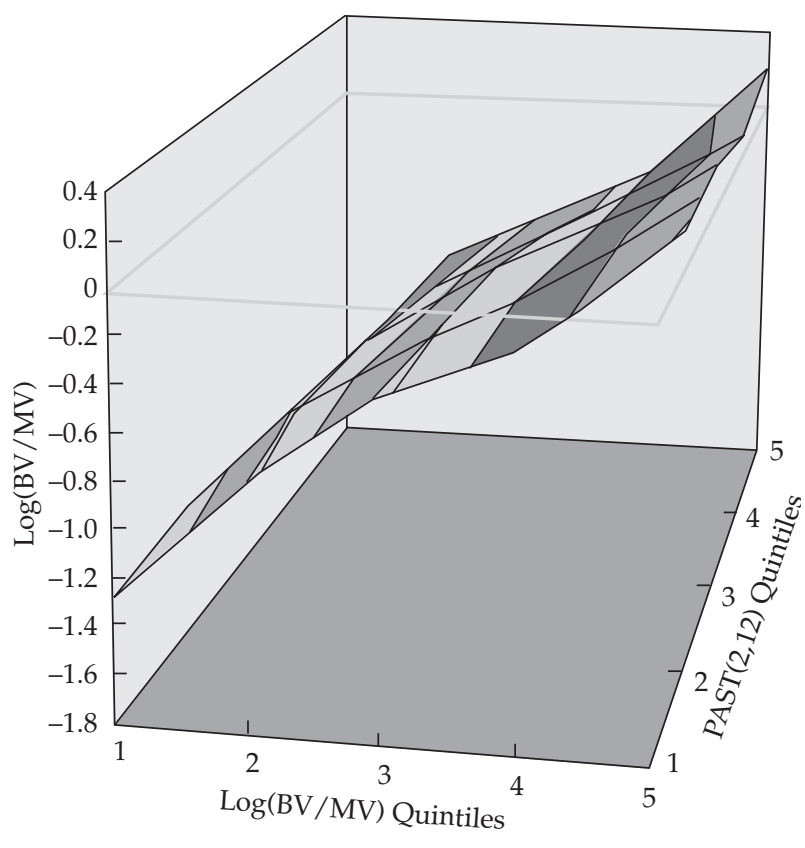

spread in PAST $(2,12){ }^{6}$

Two empirical results are of particular interest. First, value is generally a good strategy but it is weak among firms with strong momentum. Second, momentum is generally a good strategy, particularly among firms with low value. In general,

Figure 3. PAST $(2,12)$ Surface for $\operatorname{PAST}(2,12)$ and Log(BV/MV) Portfolios

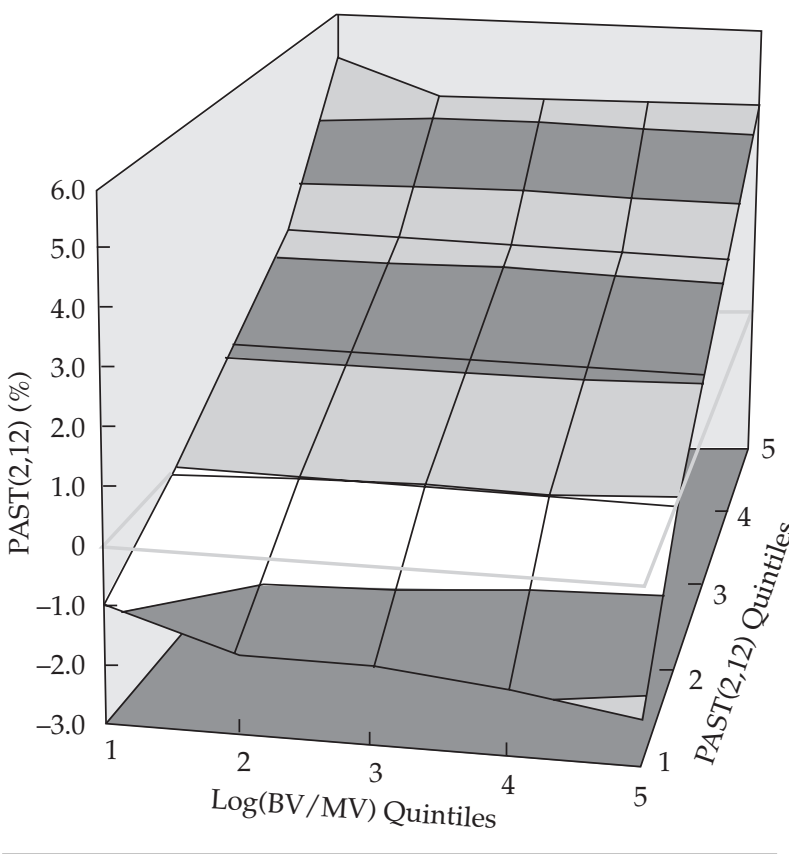


each of these strategies is nearly monotonically weaker among stocks found increasingly attractive by the other strategy.

These results are interesting, but are they statistically significant? We tested this question in the following way. First, the different cells in Table 4 are denoted as, for example, $(Q m, Q v)$, which is the portfolio that is the intersection of the Qm momentum portfolio and the $Q v$ value portfolio. That is, $(Q 1, Q 1)$ is the portfolio with low momentum and low value, $(Q 1, Q 5)$ is the portfolio with low momentum and high value, and so forth.

Using that notation, we examined two different long/short strategies:

$$
\begin{aligned}
(Q 5, Q 1)-(Q 1, Q 1)= & \text { a strategy long winners and } \\
& \text { short losers over only expen- } \\
& \text { sive firms, and } \\
(Q 5, Q 5)-(Q 1, Q 5)= & \text { a strategy long winners and } \\
& \text { short losers over only cheap } \\
& \text { firms. }
\end{aligned}
$$

The results of Table 4 indicate that momentum works better within poor-value firms. Using our notation, two different long/short strategies can be compared by looking at the following more complicated long/short portfolio (our hypothesis is that this portfolio has positive expected return):

$$
[(Q 5, Q 1)-(Q 1, Q 1)]-[(Q 5, Q 5)-(Q 1, Q 5)]>0 \text {. }
$$

Similarly, we can test whether value strategies are truly weaker for firms with strong momentum:

$$
[(Q 5, Q 5)-(Q 5, Q 1)]-[(Q 1, Q 5)-(Q 1, Q 1)]<0 .
$$

A simple manipulation shows that these two constructs are equivalent.

We can also view this hypothesis in the following manner:

$$
[(Q 5, Q 5)+(Q 1, Q 1)]-[(Q 5, Q 1)+(Q 1, Q 5)]<0 .
$$

Our test is whether this long/short portfolio has average returns of less than zero. Viewed in the form above, this test amounts to testing how the effect of increasing both momentum and value compares with the effect of increasing them one at a time. We found that $[(Q 5, Q 5)+(Q 1, Q 1)]-$ $[(Q 5, Q 1)+(Q 1, Q 5)]$ had an average return of -0.85 percent a month and a $t$-statistic of -3.50 .

This statistically significant result may be explained in one of three equivalent ways:

- The value strategy is statistically significantly stronger over loser firms than over winner firms.

- The momentum strategy is statistically significantly stronger over expensive firms than over cheap firms.

- Increasing both momentum and value simultaneously has a significantly weaker effect on stock returns than the average of the marginal effects of increasing them separately.

We next conducted similar tests for dividend yields measured relative to industry averages (Table 5). The results for $\mathrm{D} / \mathrm{P}$ are even more striking than those for $\log (\mathrm{BV} / \mathrm{MV})$. Recall that differences in $\mathrm{D} / \mathrm{P}$ can only marginally explain differences in returns across all firms (Table 3). This result, however, masks a much stronger relation. For all but the firms with the strongest recent momentum, sorting on industry-relative $\mathrm{D} / \mathrm{P}$ produces economically and statistically strong return differentials among value-weighted portfolios. Indeed, for recent loser firms (the $Q 1$ row), sorting on $\mathrm{D} / \mathrm{P}$ produces a monthly return of 92 basis points and a $t$-statistic of 4.62. For a firm that has exhibited bottom-quintile recent returns, dividend yields are a strong indicator of future returns.

The effect of $\operatorname{PAST}(2,12)$ strategies among $\mathrm{D} / \mathrm{P}$ quintiles is similar to that among $\log (\mathrm{BV} /$ MV) quintiles. PAST $(2,12)$ strategies work, in general, but they are far superior among firms with low industry-relative D/Ps. Among these low-dividend-yield firms, sorting on momentum induces a monthly return spread of 153 basis points and a $t$-statistic of 5.81 .

These differences are statistically significant; $[(Q 5, Q 5)+(Q 1, Q 1)]-[(Q 5, Q 1)+(Q 1, Q 5)]$ had an average return of -0.77 percent a month and a $t$-statistic of -3.08 . Momentum works better among low-D/P firms, and D/P works better among firms with poor momentum and does not work at all among firms with top-quintile momentum.

\section{CONCLUSION}

Both value and momentum strategies are effective, although value measures and momentum measures are negatively correlated. Thus, pursuing a value strategy entails, to some extent, buying firms with poor momentum. Equivalently, buying firms with good momentum entails, to some extent, pursuing a poor-value strategy. In most cases, holding momentum constant leads to a more effective value strategy. That is, the value strategy works best when not forced to short the effective momentum strategy. Similarly, holding value constant leads to a generally superior momentum strategy. In itself, this finding is interesting but not surprising. The interrelation, however, goes deeper.

The relations of value and momentum to future returns are not simply stronger holding the other variable constant; they are conditional upon each other. Value works, in general, but largely fails for firms with strong momentum. Momentum works, in general, but is particularly strong for expensive firms.

The spread in ex post average return produced by sorting on value measures differs depending on 
Table 5. Sorting on PAST(2,12) and D/P within Industry

\begin{tabular}{|c|c|c|c|c|c|c|}
\hline Average Value-Weighted Statistic & $\begin{array}{c}Q 1 \\
\text { (Expensive D/P) }\end{array}$ & $Q 2$ & Q3 & $Q 4$ & $\begin{array}{c}Q 5 \\
\text { (Cheap D/P) }\end{array}$ & $\begin{array}{c}Q 5-Q 1 \\
(t-\text { Statistic })^{\mathrm{a}}\end{array}$ \\
\hline \multicolumn{7}{|l|}{ Loser PAST $(2,12)$} \\
\hline Monthly return & $0.08 \%$ & $0.25 \%$ & $0.61 \%$ & $0.82 \%$ & $1.00 \%$ & $0.92 \%$ \\
\hline $\log (\mathrm{BV} / \mathrm{MV})$ & -0.63 & -0.70 & -0.69 & -0.40 & 0.01 & $(4.62)$ \\
\hline $\mathrm{D} / \mathrm{P}$ & $1.02 \%$ & $1.95 \%$ & $2.94 \%$ & $4.39 \%$ & $8.02 \%$ & \\
\hline $\operatorname{PAST}(2,12)$ & -1.30 & -1.90 & -1.64 & -1.61 & -1.83 & \\
\hline \multicolumn{7}{|l|}{$Q 2$} \\
\hline Monthly return & $0.63 \%$ & $0.57 \%$ & $0.80 \%$ & $0.94 \%$ & $1.17 \%$ & $0.54 \%$ \\
\hline $\log (\mathrm{BV} / \mathrm{MV})$ & -0.82 & -0.84 & -0.75 & -0.46 & -0.08 & $(2.91)$ \\
\hline $\mathrm{D} / \mathrm{P}$ & $1.36 \%$ & $2.28 \%$ & $3.25 \%$ & $4.70 \%$ & $7.50 \%$ & \\
\hline $\operatorname{PAST}(2,12)$ & 0.00 & 0.01 & 0.01 & 0.02 & -0.03 & \\
\hline \multicolumn{7}{|l|}{ Q3 } \\
\hline Monthly return & $0.66 \%$ & $0.75 \%$ & $0.68 \%$ & $0.89 \%$ & $1.33 \%$ & $0.67 \%$ \\
\hline $\log (\mathrm{BV} / \mathrm{MV})$ & -0.88 & -0.94 & -0.86 & -0.50 & -0.09 & $(3.80)$ \\
\hline $\mathrm{D} / \mathrm{P}$ & $1.46 \%$ & $2.24 \%$ & $3.17 \%$ & $4.53 \%$ & $7.34 \%$ & \\
\hline $\operatorname{PAST}(2,12)$ & 1.13 & 1.12 & 1.12 & 1.11 & 1.10 & \\
\hline \multicolumn{7}{|l|}{$Q 4$} \\
\hline Monthly return & $0.96 \%$ & $1.03 \%$ & $1.10 \%$ & $1.02 \%$ & $1.48 \%$ & $0.52 \%$ \\
\hline $\log (\mathrm{BV} / \mathrm{MV})$ & -0.98 & -1.04 & -0.95 & -0.53 & -0.14 & $(2.87)$ \\
\hline $\mathrm{D} / \mathrm{P}$ & $1.31 \%$ & $2.05 \%$ & $2.91 \%$ & $4.21 \%$ & $7.29 \%$ & \\
\hline $\operatorname{PAST}(2,12)$ & 2.33 & 2.30 & 2.31 & 2.24 & 2.22 & \\
\hline \multicolumn{7}{|l|}{ Winner PAST $(2,12)$} \\
\hline Monthly return & $1.61 \%$ & $1.47 \%$ & $1.25 \%$ & $1.56 \%$ & $1.76 \%$ & $0.15 \%$ \\
\hline $\log (\mathrm{BV} / \mathrm{MV})$ & -1.25 & -1.24 & -1.07 & -0.60 & -0.07 & $(0.74)$ \\
\hline $\mathrm{D} / \mathrm{P}$ & $0.83 \%$ & $1.47 \%$ & $2.34 \%$ & $3.54 \%$ & $8.80 \%$ & \\
\hline $\operatorname{PAST}(2,12)$ & 5.25 & 4.74 & 4.31 & 4.12 & 4.13 & \\
\hline $\begin{array}{l}\text { Return difference } \\
(t \text {-Statistic) }\end{array}$ & $\begin{array}{c}1.53 \\
(5.81)\end{array}$ & $\begin{array}{c}1.22 \\
(4.81)\end{array}$ & $\begin{array}{c}0.64 \\
(2.50)\end{array}$ & $\begin{array}{c}0.75 \\
(2.90)\end{array}$ & $\begin{array}{l}0.76 \\
(2.94)\end{array}$ & \\
\hline
\end{tabular}

${ }^{a}$ Zero investment portfolio that is long the $Q 5$ column entry for that row and short the $Q 1$ column entry for that row. That is, it tests a long/short portfolio strategy based on the column variable that attempts to hold the row variable constant. We report the average return on this long/short portfolio strategy and the $t$-statistic for the test of whether this average return is zero.

${ }^{b}$ Test similar to that described in Footnote a but for long/short portfolios formed on the row variable that attempt to hold the column variable constant.

the level of momentum. Nevertheless, in our actual measures of value, the spread produced by sorting on value does not vary significantly depending upon the level of momentum. Similarly, the spread in ex post average return induced by sorting on momentum varies depending on value, but the induced spread in actual momentum from sorting on momentum does not vary considerably among value quintiles.

The effect of momentum on a dividend yield value strategy is particularly startling. Sorting on industry-relative dividend yield across all firms produces at best a weak value strategy. Holding momentum constant, however, and looking at all but the largest recent-winner firms, industry-relative dividend yield is a very strong predictive variable. For example, looking only at the largest loser firms (the first row in Table 5), sorting on industryrelative $\mathrm{D} / \mathrm{P}$ leads to an average $Q 5-Q 1$ spread of 92 basis points a month $(t=4.62)$ as opposed to the 31 basis point monthly spread $(t=2.10)$ induced by sorting on D/P over all firms (Table 3).
The implication for quantitative investment strategies is interesting. Assume that the relative performance of a portfolio manager is measured against an index and that the manager attempts to maximize the trade-off between higher expected outperformance and lower volatility of outperformance (tracking error). Further assume that the manager is forming his or her portfolio based on two variables: a measure of value and a measure of momentum. In general, optimization techniques will trade off achieving higher measures of value and momentum (maximizing expected outperformance) against the goal of a more diversified portfolio (minimizing tracking error). Recognizing the relation described in this paper could lead an optimizer to own more expensive winners and cheap losers, because moving from, for instance, expensive winners to cheap winners corresponds to low marginal expected return. At this point, these practical implications are conjecture. More research on this topic is clearly appropriate. 
The implications of our results are not clear for the ongoing controversy over interpreting why these strategies work. One explanation for the success of momentum strategies is that the market is slow to react to new information. Is this explanation more or less plausible given that this slowness to react appears to be considerably more prevalent for expensive firms than for inexpensive ones?

Two differing interpretations for why value strategies work are that value represents risk versus that the market is inefficient. Value strategies work well, except among the strongest recent performers. Among the strongest recent performers, value strategies based on industry-relative BV/MV or dividend yield are ineffective. Value strategies might work because of investors' inability to price securities correctly (e.g., investors might systematically overextrapolate good or bad past results). Is it plausible that investors' abilities are much better among recent winners than among recent losers? Do investors misprice bad news more than good news?
Lakonishok et al. (1994) offered one possible explanation for the efficacy of value strategies: Investors might wish to avoid owning stocks with good value because of the perception that those are bad companies. Perhaps no such stigma applies to recent winners, no matter what their valuation measures indicate. In that case, we might expect our observed result: Value strategies largely fail among winners because the premium to owning bad companies is nonexistent. That is, there are no bad companies among recent winners. Unfortunately, a parallel story exists for the hypothesis of Fama and French (1992, 1993): Value works because it proxies for an underlying factor related to distress. Because our value measures are only proxies, the proxies could be better for loser firms than for winner firms.

The relation between value and momentum effects appears to be a strong one. These results apply directly to implementing quantitative investment strategies. The interpretation of these results will be the topic for future debate. ${ }^{7}$

\section{NOTES}

1. In general, explanations fall into three camps. One group, typified by Fama and French $(1992,1993)$, argues that value strategies work because they represent some underlying risk that is higher for value stocks, for which compensation must be made. The second camp, typified by Lakonishok et al. (1994) and Haugen (1995), believes that value strategies work because investors systematically make errors in their forecasts or because investors are uncomfortable holding value stocks. The third group, typified by Black (1993), believes that nothing really works and all of the above is data mining.

2. Defining the momentum strategy in this way avoids measurement problems induced by the bid-ask spread (Asness 1995).

3. We included firms with zero dividends in our tests. Excluding these firms has no substantial impact on our inferences.
4. This article's conclusions are strengthened but not changed by measuring the value variables intraindustry.

5. The $\log (\mathrm{BV} / \mathrm{MV})$ and $\mathrm{D} / \mathrm{P}$ entries in Table 4 and Table 5 are raw values, not industry adjusted. The spreads in industryadjusted $\log (\mathrm{BV} / \mathrm{MV})$ and $\mathrm{D} / \mathrm{P}$ also do not vary substantially among the PAST $(2,12)$ quintiles.

6. An exception is that sorting on $\log (\mathrm{BV} / \mathrm{MV})$ among only loser firms ( $Q 1$ momentum firms) produces a negative spread in PAST $(2,12)$. That is, cheaper firms within the recent loser quintile are even bigger recent losers. Of course, this result means value should work worse within this quintile, but in fact, it works better.

7. I would like to thank Kent Clark, Eugene Fama, Britt Harris, Brian Hurst, Bob Jones, Bob Krail, John Liew, Rex Sinquefield, and Ross Stevens for extremely helpful comments.

\section{REFERENCES}

Asness, C. 1995. "The Power of Past Stock Returns to Explain Future Stock Returns." Working paper, Goldman Sachs Asset Management.

Asness, C., and R. Stevens. 1995. "Intra- and Interindustry Variation in the Cross-Section of Expected Stock Returns." Working paper, Goldman Sachs Asset Management.

Black, Fischer. 1993. "Return and Beta." Journal of Portfolio Management, vol. 20, no. 1 (Fall):8-18.

Fama, Eugene F., and Kenneth R. French. 1992. "The CrossSection of Expected Returns." Journal of Finance, vol. 47, no. 2 (June):427-65.

.1993. "Common Risk Factors in the Returns on Stocks and Bonds." Journal of Financial Economics, vol. 33, no. 1 (February):3-56. 1994a. "Industry Cost of Equity." Working paper, University of Chicago (July).

1994b. “Multifactor Explanations of Asset Pricing Anomalies." Working paper, University of Chicago (July).

Haugen, Robert A. 1995. The New Finance: The Case against Efficient Markets. Englewood Cliffs, NJ: Prentice Hall.

Jegadeesh, Narasimhan, and Sheridan Titman. 1993. "Returns to Buying Winners and Selling Losers: Implications for Stock Market Efficiency." Journal of Finance, vol. 48, no. 1 (March):65-91.

Lakonishok, Josef, Andrei Shleifer, and Robert W. Vishny. 1994. "Contrarian Investment, Extrapolation, and Risk." Journal of Finance, vol. 49, no. 5 (December):1541-78. 